\title{
On the use of multi-criteria decision making methods for minimizing environmental emissions in construction projects
}

\author{
Mohamed Marzouk $^{\mathbf{a}^{*}}$ and Eslam Mohammed Abdelakder ${ }^{\mathrm{b}}$
}

${ }^{a}$ Professor of construction Engineering and Management, Structural Engineering Department, Faculty of Engineering, Cairo University, Egypt

${ }^{b}$ Ph.D. Candiate, Department of Building, Civil and Environmental Engineering, Concordia University, Montreal, QC, Canada

\begin{tabular}{l} 
C H R O N I C L E \\
\hline Article history: \\
Received June 1, 2019 \\
Received in revised format: \\
June 2, 2019 \\
Accepted June 30, 2019 \\
Available online \\
June 30, 2019 \\
\hline Keywords: \\
Environmental pollution \\
Construction industry \\
Multi-objective optimization \\
Multi-criteria decision making \\
Pareto front \\
Sensitivity analysis
\end{tabular}

\begin{abstract}
A B S T R A C T
There are huge amounts of emissions associated with construction industry during its different stages from cradle till building demolition. This study presents a methodology that integrates multi-objective optimization and multi-criteria decision making (MCDM) in order to enable construction decision-makers to select the most sustainable construction alternatives. Four objectives functions are investigated, which are: construction time, lifecycle cost, environmental impact and primary energy in order to construct the Pareto front. A novel hybrid MCDM is designed based on seven multi-criteria decision making techniques to select the best solution among the set of the Pareto optimal solutions. Sensitivity analysis is performed in order to determine the most sensitive attribute and construction stages that influence environmental emissions. The analysis illustrates that WSM, COPRAS and TOPSIS provided the best rankings of the alternatives, primary energy is the most sensitive attribute for different MCDM methods. Moreover, PROMETHEE II is the most robust MCDM method.
\end{abstract}

\section{Introduction}

Climate change is a mandatory phenomenon. Environmental pollution contributes significantly to the climate change. Greenhouse gases contribute significantly in the climate change, whereas these gases have a great influence on global temperature. According to the US National Oceanic and Atmospheric Administration, the year 2015 was recorded as the hottest year since records started in 1880. Moreover, the 16 year-period from 1998 to 2015 is considered as the warmest period ever. The increase in the heat waves occurred due to the climate change, causes heat stroke, viral fever, and dehydration (Olivier et al., 2016; Pires et al., 2016).

Many countries have perceived the importance of reducing greenhouse gases which led to some agreements and protocols, whereas the parties are required to minimize the greenhouse gas emissions below a specific baseline. Kyoto protocol is an international agreement that was introduced in December 1997 and it was linked to the United Nations Framework Convention on Climate Change to define the reduction targets in greenhouse gases. During the first commitment, the industrialized countries and the European community have agreed to reduce the greenhouse gas emissions by $8 \%$ below 1990 levels in the five-year period from 2008 to 2012. During the second commitment, the

* Corresponding author.

E-mail address: mm_marzouk@yahoo.com (M. Marzouk)

(C) 2019 by the authors; licensee Growing Science, Canada. doi: $10.5267 /$ j.dsl.2019.6.002 
industrialized countries and the European community have agreed to reduce the greenhouse gas emissions by 18\% below 1990 levels in the eight-year period from 2013 to 2020 (Heidrich et al., 2016). The United States offered to reduce the greenhouse gas emissions by 17\% below 2005 levels by 2020 at the United Nations climate change conference in Copenhagen in 2009. Then, Under Paris agreement in 2015, the United States targeted to reduce greenhouse gases by 26\%-28\% below 2005 levels by 2025 (Parker \& Karlsson, 2018).

Building sector is possibly one of the most resource-intensive industries. Building sector is regarded as one of the main contributors of the environmental emissions. The amount of greenhouse gases has increased remarkably due to the rapid growth in urbanization and inefficiencies of the existing building stock. Building sector consumes over than $30 \%$ of the global energy consumption and nearly $30 \%$ of the global energy-related $\mathrm{CO}_{2}$ emissions (Dean et al., 2016).

Based on the afore-mentioned statistics, dealing with environmental emissions became undoubtedly one of the greatest challenges in the recent century and minimizing environmental emissions produced from the building sector is immense. The main objectives of the present study are as follows:

1- Build a hybrid optimization decision-making model to select the most sustainable materials.

2- Study the robustness and sensitivity of the different multi-criteria decision making

Several efforts were done in the field of evaluation of environmental emissions and estimation. Huang et al. (2017) introduced a calculation methodology for the carbon footprint of urban buildings in Xiamen city in China. They concluded that the energy use phase and material production phase are responsible for $45 \%$ and $40 \%$ of the carbon footprint, respectively. They highlighted that the implementation of low-carbon strategies can result in the reduction of energy consumption of urban buildings by $2.98 \%$ in 2020 . Barati and Shen (2017) presented a methodology to minimize the operation emissions for on-road construction equipment. They stated that the emissions of the construction equipment increase significantly by increasing the payload of the equipment and the road slope. Seo et al. (2016) analyzed the $\mathrm{CO}_{2}$ emissions produced from the material production phase, transportation phase, and construction phase. They highlighted that the manufacturing phase is the largest contributor of $\mathrm{CO}_{2}$ emissions with $93.4 \%$ followed by construction phase, and finally the transportation phase.

Abdallah et al. (2015) designed an optimization model that is capable of selecting the optimum building upgrade measures by minimizing the energy consumption while taking into consideration the budget constraints. The optimization model incorporates the analysis of the following systems, which are: interior and exterior lighting systems, HVAC (heating, ventilation and air conditioning) systems, water heaters, hand dryers, and renewable energy systems. Cho and Chae (2016) analyzed the emissions produced from low-carbon buildings and compared it with the emissions produced from the reference buildings. They highlighted that the low-carbon buildings can result in a $25 \%$ reduction in the carbon emissions. They illustrated that operation and maintenance phase represents the highest weight of $\mathrm{CO}_{2}$ emissions followed by manufacturing phase while construction phase represents the least contributor to $\mathrm{CO}_{2}$ emissions.

Motuzienệ et al. (2016) compared between the environmental impacts of three types of envelopes which are: masonry, log, and timber frame buildings. Several attributes were considered such as life cycle cost, primary energy consumption, global warming, and ozone layer depletion. The weights of attributes were obtained using Analytical Hierarchy Process. Based on the previous literature review, most research contributions had the following limitations which are: 1) some researches did not take into account all the different phases of construction project in the calculation of emissions and energy consumption, and 2) some researches did not consider air pollutants which constitute in the total equivalent amount of carbon dioxide such as carbon dioxide, methane, nitrous oxide, and fluorinated gases. Most researches focused on carbon dioxide emissions only, and 3) most researches did not consider other types of environmental emissions such as particular matter, sulfur dioxide, etc. 


\section{Research methodology}

A methodology is proposed in order to select the best scenario to construct the project. The proposed model considers different project components such as plain concrete, reinforced concrete, beams, slabs, walls, etc. Each project component is divided into a group of alternatives. The proposed model accounts for different project phases which are: manufacturing phase, transportation on-site and off-site phases, construction phase, maintenance phase, recycling/reuse phase, and deconstruction/demolition. The steps of the proposed model are depicted in Fig. 1. The set of all possible alternatives for different project components are depicted in Table 1.

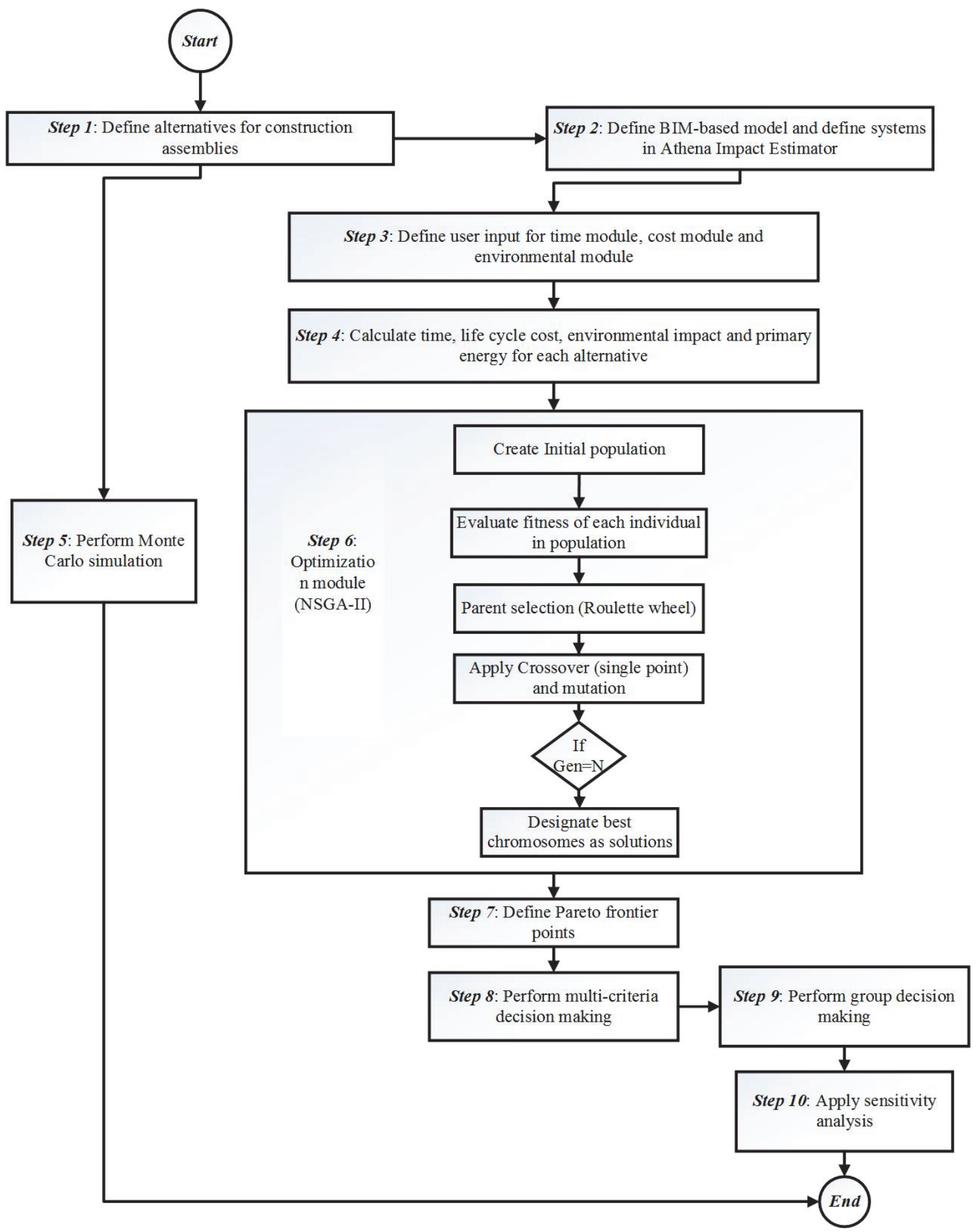

Fig. 1. Framework of the proposed methodology 


\section{Table 1}

Available alternatives of the case study

\begin{tabular}{|c|c|c|}
\hline Project Assemblies & Alternative No. & Alternative Description \\
\hline \multirow[t]{6}{*}{ Excavation } & 1 & 5 crews \\
\hline & 2 & 6 crews \\
\hline & 3 & 7 crews \\
\hline & 4 & 8 crews \\
\hline & 5 & 9 crews \\
\hline & 6 & 10 crews \\
\hline \multirow[t]{6}{*}{ Plain concrete } & 1 & 4 crews of carpentering +1 crew of pouring concrete - concrete type 1 (average fly ash) \\
\hline & 2 & 5 crews of carpentering +2 crews of pouring concrete -concrete type 1(average fly ash) \\
\hline & 3 & 4 crews of carpentering +1 crew of pouring concrete - concrete type 2 ( $25 \%$ fly ash) \\
\hline & 4 & 5 crews of carpentering +2 crews of pouring concrete -concrete type $2(25 \%$ fly ash $)$ \\
\hline & 5 & 4 crews of carpentering +1 crew of pouring concrete - concrete type 3 ( $35 \%$ fly ash) \\
\hline & 6 & 5 crews of carpentering +2 crews of pouring concrete -concrete type $3(35 \%$ fly ash $)$ \\
\hline \multirow[t]{6}{*}{ Reinforced concrete } & 1 & $\begin{array}{l}4 \text { crews of carpentering }+15 \text { crews of fixing reinforcement }+1 \text { crew of pouring concrete - } \\
\text { concrete type } 1 \text { (average fly ash) }\end{array}$ \\
\hline & 2 & $\begin{array}{l}5 \text { crews of carpentering }+17 \text { crews of fixing reinforcement }+2 \text { crews of pouring concrete - } \\
\text { concrete type } 1 \text { (average fly ash) }\end{array}$ \\
\hline & 3 & $\begin{array}{l}4 \text { crews of carpentering }+16 \text { crews of fixing reinforcement }+1 \text { crew of pouring concrete - } \\
\text { concrete type } 2(25 \% \text { fly ash })\end{array}$ \\
\hline & 4 & $\begin{array}{l}5 \text { crews of carpentering }+17 \text { crews of fixing reinforcement }+2 \text { crews of pouring concrete - } \\
\text { concrete type } 2(25 \% \text { fly ash })\end{array}$ \\
\hline & 5 & $\begin{array}{l}4 \text { crews of carpentering }+16 \text { crews of fixing reinforcement }+1 \text { crew of pouring concrete - } \\
\text { concrete type } 3(35 \% \text { fly ash) }\end{array}$ \\
\hline & 6 & $\begin{array}{l}5 \text { crews of carpentering }+17 \text { crews of fixing reinforcement }+2 \text { crews of pouring concrete - } \\
\text { concrete type } 3(35 \% \text { fly ash) }\end{array}$ \\
\hline \multirow[t]{4}{*}{ Backfilling } & 1 & 10 crews \\
\hline & 2 & 11 crews \\
\hline & 3 & 12 crews \\
\hline & 4 & 13 crews \\
\hline \multirow[t]{5}{*}{ Foundations' insulation } & 1 & Blown cellulose \\
\hline & 2 & Mineral wool batt R50 \\
\hline & 3 & Polyiscoyanurate foam \\
\hline & 4 & Fiberglass batt R50 \\
\hline & 5 & Polystyrene extruded \\
\hline \multirow[t]{7}{*}{ Slabs } & 1 & Cast in situ Concrete $30 \mathrm{MPa}$ with average fly ash \\
\hline & 2 & Cast in situ Concrete $30 \mathrm{MPa}$ with $25 \%$ fly ash \\
\hline & 3 & Cast in situ Concrete $30 \mathrm{MPa}$ with $35 \%$ fly ash \\
\hline & 4 & Wood based system \\
\hline & 5 & Steel based system \\
\hline & 6 & Glulam based system \\
\hline & 7 & Precast concrete \\
\hline \multirow[t]{6}{*}{ Columns } & 1 & Softwood lumber \\
\hline & 2 & Glulam \\
\hline & 3 & Laminated veneer lumber \\
\hline & 4 & Hollow structural steel \\
\hline & 5 & Precast concrete \\
\hline & 6 & Cast in situ concrete \\
\hline \multirow[t]{5}{*}{ Beams } & 1 & Glulam \\
\hline & 2 & Laminated veneer lumber \\
\hline & 3 & Wide flange \\
\hline & 4 & Precast concrete \\
\hline & 5 & Cast in situ concrete \\
\hline \multirow[t]{15}{*}{ Walls } & 1 & Cast in situ Concrete $30 \mathrm{MPa}$ with average fly ash \\
\hline & 2 & Cast in situ Concrete $30 \mathrm{MPa}$ with $25 \%$ fly ash \\
\hline & 3 & Cast in situ Concrete $30 \mathrm{MPa}$ with $35 \%$ fly ash \\
\hline & 4 & Wood based system \\
\hline & 5 & Steel based system \\
\hline & 6 & Insulated concrete form (average fly ash) \\
\hline & 7 & Insulated concrete form ( $25 \%$ fly ash) \\
\hline & 8 & Insulated concrete form ( $35 \%$ fly ash) \\
\hline & 9 & Structural insulated panels \\
\hline & 10 & Precast concrete (average fly ash) \\
\hline & 11 & Precast concrete ( $25 \%$ fly ash) \\
\hline & 12 & Precast concrete ( $35 \%$ fly ash) \\
\hline & 13 & Curtain wall (metal spandrel panels) \\
\hline & 14 & Curtain wall (glass spandrel panels) \\
\hline & 15 & Concrete bricks \\
\hline \multirow[t]{3}{*}{ Thermal insulation } & 1 & Polyethylene 3 mil thickness \\
\hline & 2 & Polyethylene 6 mil thickness \\
\hline & 3 & Polypropylene scrim Kraft \\
\hline
\end{tabular}


Table 2

Available alternatives of the case study (Continued)

\begin{tabular}{|c|c|c|}
\hline Project Assemblies & Alternative No. & Alternative Description \\
\hline \multirow[t]{3}{*}{ Painting } & 1 & Alkyd solvent based paint \\
\hline & 2 & Vamish solvent based paint \\
\hline & 3 & Latex water based paint \\
\hline \multirow[t]{15}{*}{ Cladding } & 1 & cedar cladding \\
\hline & 2 & Concrete bricks cladding \\
\hline & 3 & Vinyl cladding \\
\hline & 4 & Fiber cement cladding \\
\hline & 5 & Insulated metal panels cladding \\
\hline & 6 & Metal cladding \\
\hline & 7 & Modular bricks cladding \\
\hline & 8 & Natural stone cladding \\
\hline & 9 & Ontario bricks cladding \\
\hline & 10 & Precast panels cladding \\
\hline & 11 & Precast insulated panels with brick veneer cladding \\
\hline & 12 & Precast insulated panels \\
\hline & 13 & Spruce cladding \\
\hline & 14 & Stucco cladding \\
\hline & 15 & Pine cladding \\
\hline \multirow[t]{8}{*}{ Ceiling finishing } & 1 & Gypsum fiber BD 1/2" \\
\hline & 2 & Gypsum fiber BD 5/8" \\
\hline & 3 & Gypsum fire rated type $1 / 2 "$ \\
\hline & 4 & Gypsum fire rated type $5 / 8 "$ \\
\hline & 5 & Gypsum regular type $1 / 2 "$ \\
\hline & 6 & Gypsum regular type $5 / 8^{\prime \prime}$ \\
\hline & 7 & Gypsum moisture resistant type $1 / 2 "$ \\
\hline & 8 & Gypsum moisture resistant type 5/8" \\
\hline \multirow[t]{12}{*}{ Roofing system } & 1 & Black EPDM membrane 60 mil thickness. \\
\hline & 2 & White EPDM membrane 60 mil thickness \\
\hline & 3 & Clay tiles \\
\hline & 4 & Concrete tiles \\
\hline & 5 & PVC membrane 48 mil thickness \\
\hline & 6 & Standard modified bitumen membrane \\
\hline & 7 & Ballast (aggregate stones) membrane \\
\hline & 8 & Extreme white TPO membrane $60 \mathrm{mil}$ \\
\hline & 9 & Extreme white TPO membrane $70 \mathrm{mil}$ \\
\hline & 10 & Extreme white TPO membrane $80 \mathrm{mil}$ \\
\hline & 11 & white TPO membrane $60 \mathrm{mil}$ \\
\hline & 12 & white TPO membrane $80 \mathrm{mil}$ \\
\hline
\end{tabular}

The model inputs are divided into two main clusters which are: model external inputs and model user inputs. The second step is to develop a BIM-based model using Autodesk Revit (Autodesk Revit 2015) and to define systems in Athena Impact Estimator (Athena Impact Estimator 5.0.0105). The BIM model constitutes a database. Revit DB link is a plug-in that enables all data concerning 3D model to be sent to Microsoft Access. A SQL statement is written inside the developed model to retrieve the data of the building information model from Microsoft Access to the proposed application. Athena Impact Estimator calculates different environmental emissions which are; greenhouse gases footprint, acidification potential, human health $(\mathrm{HH})$ particulate, eutrophication potential, ozone depletion and smog for different project life cycle phases. Different properties of building systems should be defined in Athena Impact Estimator including; material type, geometry of building systems and size of reinforcement.

The proposed application calculates time, life cycle cost, environmental impact and primary energy of each scenario independently. The third step is to define the needed user inputs for each module in the proposed application. The proposed application is divided into three modules which are time module, cost module and environmental module. The windows application is developed using C\#.net programming language. The user is asked to determine certain inputs in each module. The user is asked to enter number of crews, productivity of each crew and nature of crews (single-based crews or rangebased crews) for each scenario for the time module. Interface of user input for the time module is depicted in Figure 2. "Check values" button is used to make sure that all the needed data are entered. For the cost module, the user is asked to enter some information to calculate total life cycle cost as Minimum attractive rate of return (MARR), maintenance cost per year (if exist), maintenance cost per a specific period of time (if exist) and to determine this period of time (e.g. 2 years, 5 years, 10 years, 
25 years). The user is also asked to enter maintenance cost at a certain year if exist and to determine this year. For the environmental module, the user is asked to enter relative weights of the six different environmental emissions ( $W 1, W 2, W 3, W 4, W 5$, and $W 6)$.

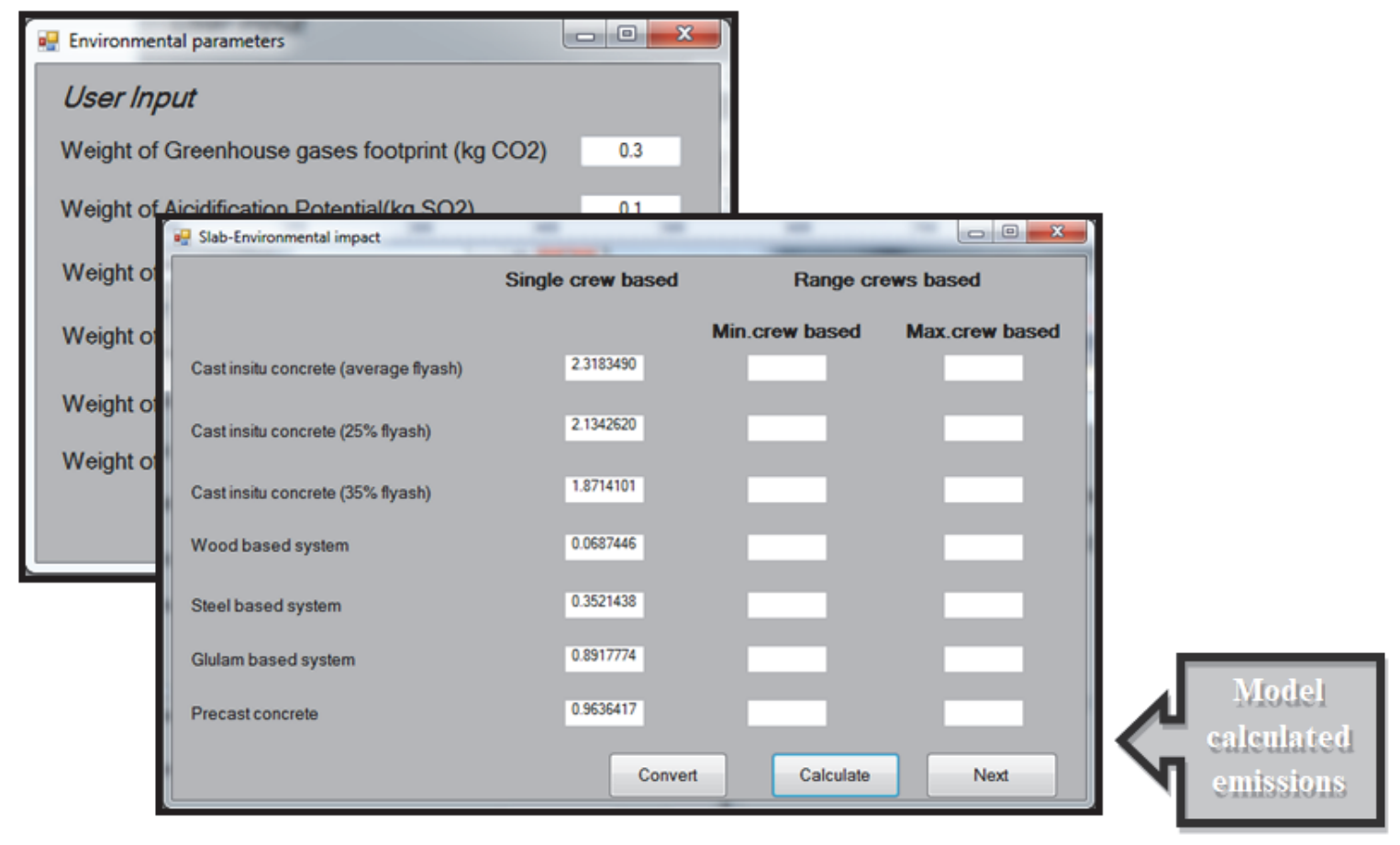

Fig. 2. Calculated environmental impact of the developed model

The proposed optimization model utilizes the non-dominated sorting genetic algorithm (NSGA-II). The model applies multi-objective optimization with four objective functions. The first objective function is to minimize total project duration and it is calculated using Equation 1. This function takes into consideration different relationships between construction activities. The model uses the critical path method (CPM) to calculate total project duration. The second objective function is to minimize total project lifecycle cost and it is calculated using Eq. (2). The third objective function is to minimize total project emissions and it is calculated using Eq. (3). The fourth objective function is to minimize total project primary energy and it is calculated using Eq. (4).

$$
\begin{gathered}
T=\min T P T=\min C P\left(\text { Time }_{m}\right) \\
C=\min T P C=\min \sum_{m=1}^{n} \text { Cost }_{m} \\
E I=\min T P E I=\min \sum_{m=1}^{n} E_{t o t_{m}} \\
E N=\min T P E N=\min \sum_{m=1}^{n} E n e_{m}
\end{gathered}
$$

where;

$m$ represents activities of construction project. TPT, TPC, TPEI and TPEN represent total project time, cost, environmental impact and primary energy, respectively. Time, Cost, Etot and Ene 
represent duration, cost, environmental impact and primary energy of a construction activity. $C P$ represents the critical path operator.

The purpose of multi-criteria decision making is to rank the best scenarios of the Pareto frontier. Seven multi-criteria decision making methods were investigated. Each decision-making technique depends on a certain concept, parameter and numerical measure in ranking alternatives. Thus, each decisionmaking technique provides a different ranking from the other. For instance, TOPSIS utilizes the Euclidean distances to compare between the alternatives using the positive and negative ideal solutions as references, GRA utilizes the grey relational grade to analyze the reference series and the alternative series while ELECTRE I technique is based on outranking relations using pair wise comparisons. Another reason for the different rankings obtained from the MCDM methods is that some MCDM methods are function of some parameters that can influence the final ranking of the alternatives. For example, GRA is dependent on the distinguishing coefficient, which is between 0 and 1 while VIKOR is a function of the maximum group utility coefficient. The proposed model investigates the degree of influence of the pre-mentioned parameters on the final ranking of alternatives.

Time, lifecycle cost, environmental impact and primary energy are the attributes of multi-criteria decision making techniques. Shannon entropy method is used as the weight determination methodology to calculate the weights of attributes. Group decision making is performed in order to aggregate the results obtained from the seven multi-criteria decision making techniques. Group decision making provides a consensus and final ranking for solutions. Inferred group decision- making is obtained using both additive ranking rule and multiplicative ranking rule. Then, a correlation matrix is designed in order to investigate the correlation between each two MCDM methods using Spearman's rank correlation coefficient and Kendall tau rank correlation. A robustness measure is introduced for each MCDM to test its stability against the variations in the data. Sensitivity analysis is performed to determine the most sensitive attribute, the most sensitive alternative, and the most sensitive stage of the construction process that affects environmental emissions. The introduced sensitivity analysis provides a full ranking of attributes and alternatives based on sensitivity coefficients and sensitivity measures. Finally, Monte Carlo sampling method is utilized to consider the uncertainties and variations in the calculation of greenhouse gases. The features of the proposed model are demonstrated by a case study of academic building.

\section{Multi-criteira decision making techniques}

Multi-criteria decision-making methods are a group of methods that allow the aggregation and consideration different attributes in order to rank alternatives and select the best one ${ }^{41}$. Seven different decision-making techniques are used in this research to rank the alternatives. Evaluation criteria in MCDM can be divided into two main clusters which are (Dragisa et al., 2013): 1) benefit criteria where the higher measure of performance is the better one, 2) cost criteria where the lower measure of performance is the better one. These techniques are; Weighted Sum Method (WSM), COPRAS, Grey Relational Analysis (GRA), Technique for Order Preference by Similarity to Ideal Solution (TOPSIS), VIKOR, Elimination and Choice Translating Reality (ELECTRE I) and (Preference Ranking Organization Method for Enrichment Evolution) PROMETHEE II. The following subsections provide

an overview of the fundamental calculations of some of the pre-mentioned multi-criteria decision making techniques. More details about TOPSIS, GRA, VIKOR and TOPSIS can be found in Triantaphyllou et al. (1998); Kuo et al. (2008); Chen et al. (2012) and Cristóbal et al. (2011). The computation of weights of attributes using Shannon entropy and analytical hierarchy process can be adopted from Akyene et al. (2012) and Saaty (2008).

\subsection{COPRAS}

COPRAS is defined as complex proportional assessment. COPRAS method assumes direct, proportional dependence of significance and priority of investigated alternatives in a system containing 
attributes. The preference of alternative is calculated taking into concern the positive and negative characteristics of alternatives. COPRAS method calculates the utility degree of each alternative as per below procedure. The normalization process can be performed using Equation 5 (Mulliner et al., 2013).

$$
d_{i j}=\frac{x_{i j}}{\sum_{i=1}^{m} x_{i j}} q_{j}
$$

where;

$x_{i j}$ is the value that corresponds measure of performance of the $i$-th alternative and $j$-th attribute and $q_{j}$ represents the weight of each attribute. $d_{i j}$ represents dimensionless weighted value. The weights of attributes can be calculated using Eq. (6).

$$
q_{j}=\sum_{i=1}^{m} d_{i j}
$$

The alternatives are distinguished by beneficial (maximizing) attributes and cost (minimizing) attributes. The sum of weighted normalized values for both the beneficial and cost attributes can be obtained using Eqs. (7-8), respectively.

$$
\begin{aligned}
& s_{i}^{+}=\sum_{j=1}^{n} d_{i j} \\
& s_{i}^{-}=\sum_{j=n+1}^{k} d_{i j}
\end{aligned}
$$

where;

$s_{i}^{+}$refers to the sum of elements in the weighted normalized matrix that corresponds to beneficial attributes. On the other hand, $s_{i}^{-}$refers to the sum of elements in the weighted normalized matrix that corresponds to cost attributes. The relative significance $\left(Q_{i}\right)$ is calculated for each alternative using Eq. (9).

$$
Q_{i}=s_{i}^{+}+\frac{s_{\min }^{-} \times \sum_{i=1}^{m} s_{i}^{-}}{s_{i}^{-} \times \sum_{i=1}^{m} \frac{s_{\min }^{-}}{s_{i}^{-}}}=s_{i}^{+}+\frac{\sum_{i=1}^{m} s_{i}^{-}}{s_{i}^{-} \times \sum_{i=1}^{m} \frac{1}{s_{i}^{-}}}
$$

The utility degree of each alternative is calculated and the best alternative is the alternative with the highest utility degree. The utility degree for each alternative is computed using Equation 10.

$$
N_{j}=\frac{Q_{i}}{Q_{\max }} \times 100 \%
$$

where;

$N_{j}$ indicates the utility degree of each alterative. 


\subsection{PROMETHEE II}

PROMETHEE is defined as "Preference Ranking Organization Method for Enrichment Evolution". Visual PROMETHEE software is used to solve multi-criteria decision-making problems using PROMETHEE II (Visual PROMETHEE 2015). Visual PROMETHEE was developed using VPSolutions under the supervision of Professor Bertrand Mareschal. Visual PROMETHEE version 1.4 is used. There are six types of preference functions used in PROMETHEE method which are: U-shaped, V-shaped, usual, linear, level and Gaussian. The preference function is assigned to each attribute. The shape of preference function determines two important thresholds which are: indifference threshold $(Q)$ and preference threshold $(P)$. Preference threshold represents the smallest deviation that is considered decisive. Indifference threshold represents the largest deviation that is considered negligible. The preference function used in the discussed case study is the linear function. The alternatives in PROMETHEE II will be ranked according to net flow. The higher the net flow the better the alternative will be (Bogdanovic et al., 2012).

\section{Group decision making}

Two group decision making techniques are introduced in order to integrate and aggregate different rankings obtained from the different decision-making techniques into one ranking. The first method is called Additive Ranking Rule where $r^{G}$ which represents ranking obtained for each alternative by group decision making method is estimated using Eq. (11). The second method is called Multiplicative Ranking Rule and the index $r^{G}$ is calculated using Eq. (12).

$$
r^{G}=1-\frac{\sum_{D M=1}^{G} w_{D M} \times r_{D M}}{G}
$$

where;

$r_{D M}$ represents the ranking obtained for each alternative from decision making method. $w_{D M}$ represents the relative influence of each decision making method. $G$ represents the number of decision making techniques.

$$
r^{G}=\prod_{D M=1}^{G}\left(w_{D M} \times r_{D M}\right)^{\frac{1}{G}}
$$

Where;

$r_{D M}$ represents the ranking obtained for each alternative from each decision making method. $w_{D M}$ represents the relative influence of each decision making method. $G$ represents the number of decision making methods.

\section{Robustness measure}

Not many efforts have been in the field of testing robustness of decision making methods. Sengupta (1991) introduced the concept of robustness in Data Envelopment Analysis. The concept integrated the idea of stability of the model to small variations in parameters and the idea of prudence with regard to possible bad versions. Robustness measure $(R M)$ is a term that is used in order to test the robustness of multi-criteria decision-making techniques against the change in weights of attributes.

A robust model is a strong built or strong formed model where if the inputs and parameters of the model are changed by certain values, the impact of the change will be very small, and the model will remain stable against perturbations in the data. Group of experiments are conducted to each attribute. Each experiment represents a certain change in the weight of a certain attribute. Assume that the change in weight of second attribute is represented by $(\Delta)$, then the weight of this attribute $\left(w_{2}{ }^{\prime}\right)$ will be $w_{2}+\Delta$. The weights of other attributes are calculated using Equation 13, so that the sum of weights of attributes will be equal to $100 \%$. The number of experiments done for each attribute should be equal. 


$$
w_{j}^{\prime}=\frac{1-w_{c}^{\prime}}{1-w_{c}} \times w_{j}
$$

where,

$w_{c}$ and $w_{c}^{\prime}$ represent the original and modified weight of the main attribute, respectively.

The value of robustness measure ranges from 0 to 1 . The robustness measure can be measured using average Spearman's rank correlation coefficient and Kendall's tau rank correlation coefficient. Robustness measure obtained from Spearman's rank correlation coefficient and Kendall's tau rank correlation is obtained using Equations 14 and 15, respectively. Robustness measure can be calculated using Eq. (16).

$$
\begin{aligned}
& R M_{1}=\frac{\sum_{f=1}^{F} R_{f}}{F} \\
& R M_{2}=\frac{\sum_{f=1}^{F} \mathrm{~T}_{f}}{F} \\
& R M=\frac{R M_{1}+R M_{2}}{2}
\end{aligned}
$$

where;

$R M_{1}$ and $R M_{2}$ refer to robustness measure obtained from spearman's rank correlation coefficient and Kendall's tau rank correlation, respectively. $R M$ refers to overall robustness measure. $F$ refers to number of experiments used to test the robustness of the decision making technique. $R_{F}, \mathrm{~T}_{f}$ refers to the spearman's rank correlation coefficient and Kendall's tau rank correlation coefficient obtained from the $f$-th experiment, respectively. The computation methods of Spearman's Rank Correlation Coefficient and Kendall's tau rank correlation coefficient can be adopted from Banerjee and Ghosh (2013), and Chakraborty et al. (2013).

The proposed method utilized the method introduced by Triantaphyllou and Sánchez (1997). They performed sensitivity on WSM, WPM and AHP. They introduced methodologies to determine the most sensitive attribute and measure of performance. The most sensitive element can be defined as the element that is if it is changed by smaller value, greater impact will occur. In our case, the impact is represented by the change in ranking of alternatives. The sensitivity analysis based on WSM is divided into two main clusters: determine the most critical criteria and determining the most critical measure of performance.

\section{Case study building}

\subsection{Case Description}

The case study is a university project in Saudi Arabia which consists of three floors. Area of one floor is approximately $9100 \mathrm{~m}^{2}$. The BIM model is shown in Figure 3. For the considered case, the weights for greenhouse gases, sulfur dioxide, particular matter, eutrophication particles, ozone depleting particles and smog potential, are $W 1=0.3, W 2=0.1, W 3=0.1, W 4=0.1, W 5=0.1$, and $W 6=0.3$, respectively. The minimum attractive rate of return (MARR) is assumed $6 \%$. Maintenance cost per year is assumed $1 \%$ of the initial cost. Maintenance cost per specific period is $1 \%$ of the initial cost every 25 years. Single payments are assumed for each assembly. The proposed model considers 101 scenarios for all assemblies. 


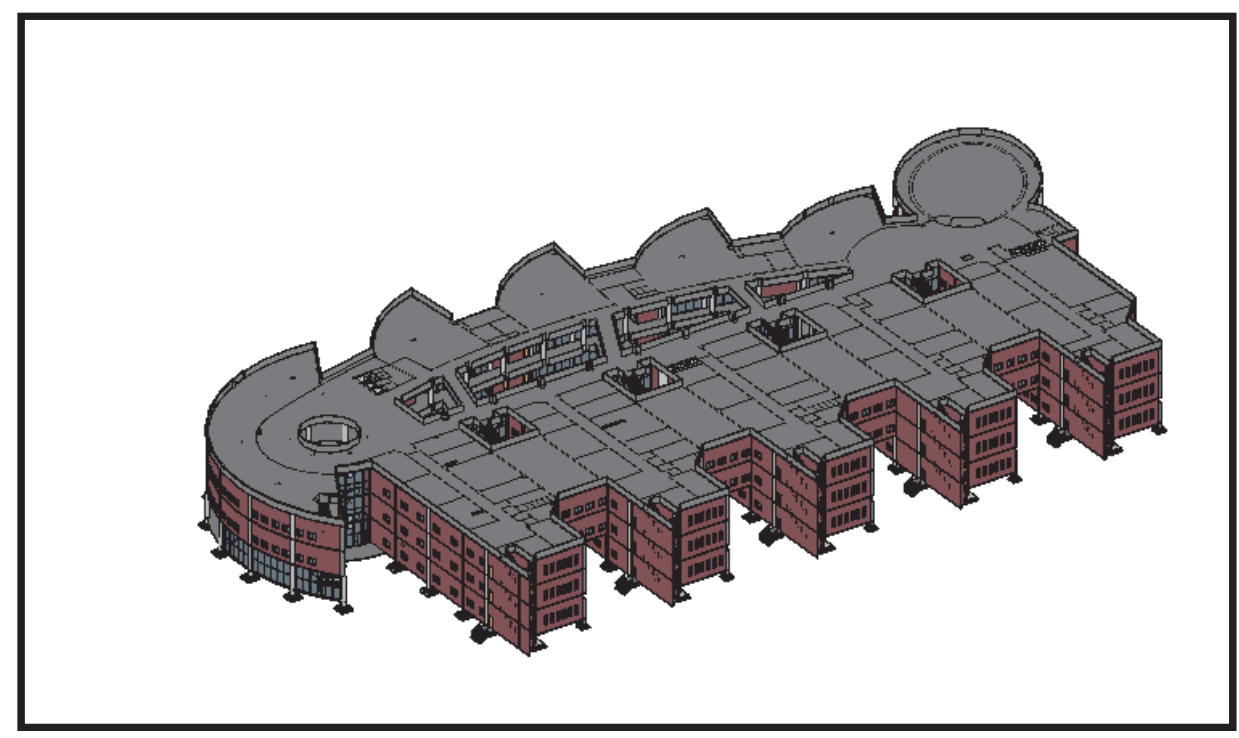

Fig. 3. BIM model of the case study

\subsection{Results and Discussion}

The case study takes into consideration $1.76 \times 10^{11}$ possible combinations. This number represents the maximum number of the possible combinations. This number represents the search space that the genetic algorithm tries to explore and find the optimum solutions within it. This number is equal to the multiplication of the alternatives in each construction assembly by each other. An evolutionary genetic algorithm optimization is performed in order to select the most feasible alternative for each assembly based on minimizing time, life cycle cost, environmental impact and energy consumption. The population size is assumed 1500 . The crossover rate is assumed 0.9. Single point crossover is used. The mutation rate is assumed 0.05 . Tournament selection strategy is implemented for parent selection. Number of generations is assumed 750. After applying the genetic algorithm, 1500 optimum solutions are obtained. Results of the optimum solutions are depicted in Figure 4.

As mentioned the optimization problem is a 4-Dimensional objective function. The optimum solutions are displayed in 3-Dimensional figure. Thus, there are four possible combinations of the 3-Dimensional figures. As shown in Figure 4, each optimum solution is accompanied by a corresponding construction time, lifecycle cost, environmental impact and primary energy consumption. The terms T, C, EI and EN stand for time, life cycle cost, environmental impact, and primary energy, respectively. Sample of the obtained solutions is shown in Table 2. A code is written in Matlab in order to select the Pareto frontier points. The Pareto frontier points represent a set of non-dominated solutions obtained by the optimization algorithm. The Pareto front is composed of 72 non-dominated solutions, which represent the set of non-inferior solutions. The best solution, among the set of non-dominated solutions, is obtained using multi-criteria decision making methods as shown in the next lines. 


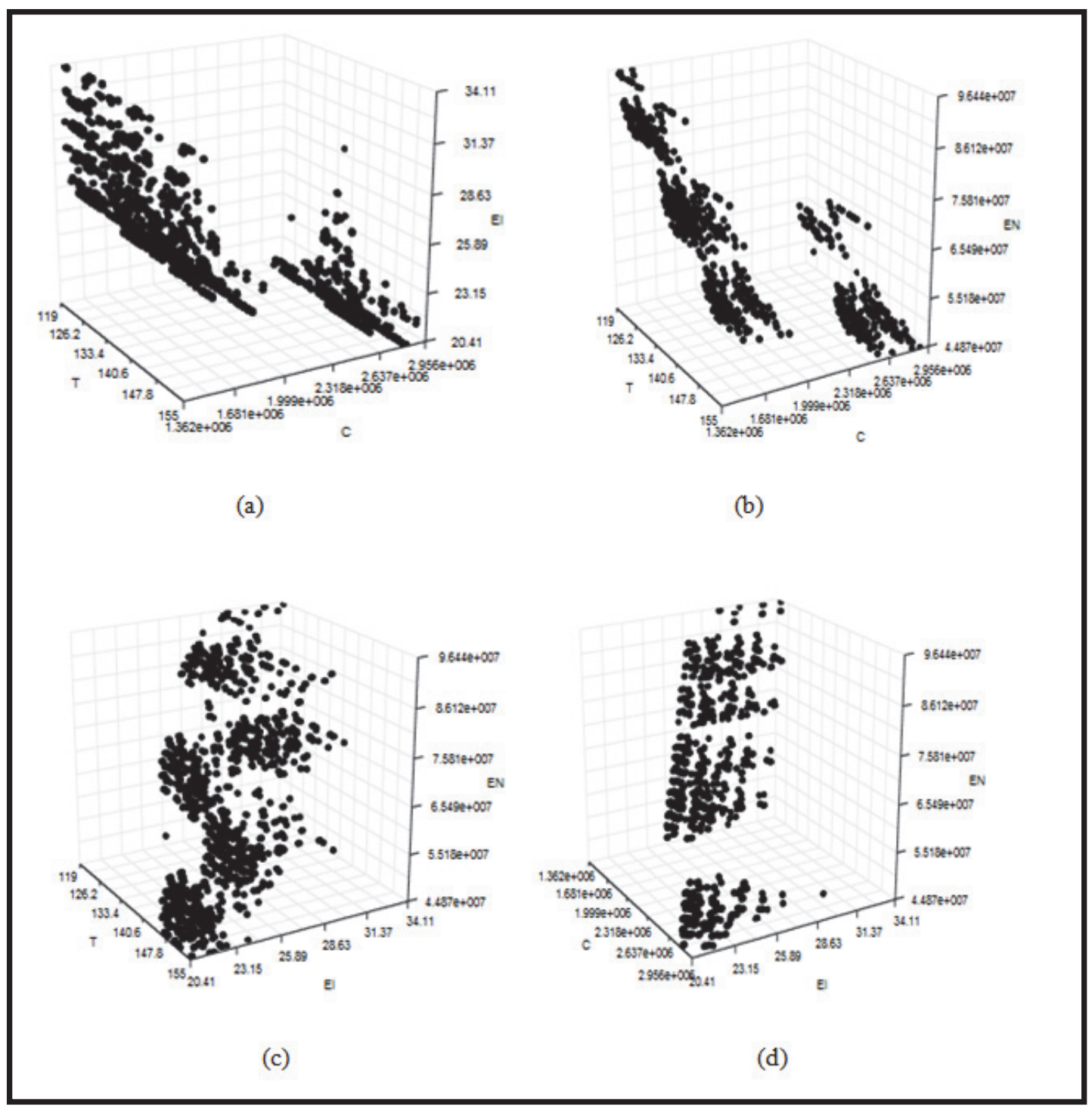

Fig. 4. Generated solutions from the optimization module

Table 3

Sample of optimal solutions

\begin{tabular}{lllllc}
\hline Alternative no. & Associated scenarios & $\begin{array}{l}\text { Total } \\
\text { Duration } \\
\text { (days) }\end{array}$ & $\begin{array}{l}\text { Lifecycle } \\
\text { Cost } \\
\text { (LE/year) }\end{array}$ & $\begin{array}{l}\text { Environmental } \\
\text { Impact }\end{array}$ & $\begin{array}{l}\text { Primary } \\
\text { Energy (MJ) }\end{array}$ \\
\hline 98 & $6,6,6,4,4,7,1,2,15,12,3,2,2,7,1$ & 121 & $1,435,604$ & 27.85 & $88,861,419$ \\
240 & $6,6,6,4,4,7,1,2,15,12,3,2,6,7,1$ & 124 & $1,470,030$ & 26.95 & $85,848,218$ \\
312 & $6,6,6,4,4,7,3,2,15,4,3,2,2,7,1$ & 125 & $1,641,896$ & 26.04 & $68,884,647$ \\
825 & $6,6,6,4,4,6,3,2,15,4,3,2,2,7,1$ & 140 & $1,606,944$ & 25.75 & $58,529,871$ \\
1081 & $6,6,6,4,4,4,1,2,15,4,3,2,2,7,1$ & 143 & $2,560,041$ & 22.42 & $50,105,692$ \\
1293 & $6,6,6,2,4,4,3,3,4,4,3,2,6,7,1$ & 147 & $2,820,051$ & 20.55 & $45,589,778$ \\
\hline
\end{tabular}

Shannon entropy method is used as the weight determination methodology to calculate the weights of decision making attributes (time, lifecycle cost, environmental impact and primary energy). The entropy value, variation coefficient and weight of each attribute are shown in Table 3. Calculations show that life cycle cost constitutes the largest weight by $48.12 \%$ while total duration represents the smallest weight by $3.76 \%$. Seven multi-criteria decision making techniques are used to rank alternatives. The seven techniques are WSM, TOPSIS, GRA, VIKOR, COPRAS, ELECTRE I and PROMETHEE II. Each multi-criteria decision making technique proposes a certain ranking of 
alternatives based on specific numerical measures. Therefore, different rankings are obtained. The rankings of 72 alternatives obtained from each decision making technique are illustrated in Table 4. As per Table 4, different rankings are obtained for each alternative. For instance, the rankings of alternative ID 1490 based on WSM, TOPSIS, GRA, VIKOR, COPRAS, ELECTRE I and PROMETHEE II are $72,39,67,72,72,44$ and 37 , respectively.

\section{Table 4}

Entropy value, variation coefficient and weight of attributes

\begin{tabular}{|c|c|c|c|c|}
\hline Terms & $\begin{array}{l}\text { Total Duration } \\
\text { (days) }\end{array}$ & $\begin{array}{l}\text { Lifecycle Cost } \\
\text { (LE/year) }\end{array}$ & Environmental Impact & $\begin{array}{l}\text { Primary Energy } \\
(\mathrm{MJ})\end{array}$ \\
\hline$e_{j}$ & 0.999362 & 0.991826 & 0.998744 & 0.993083 \\
\hline$d_{j}$ & 0.000638 & 0.008174 & 0.001256 & 0.006917 \\
\hline$w_{j}$ & $3.76 \%$ & $48.12 \%$ & $7.4 \%$ & $40.72 \%$ \\
\hline
\end{tabular}

Table 5

Ranking of alternatives obtained from seven decision making techniques

\begin{tabular}{|c|c|c|c|c|c|c|c|}
\hline Alternative no. & WSM & GRA & TOPSIS & VIKOR & COPRAS & ELECTRE I & PROMETHEE II \\
\hline 1018 & 63 & 71 & 64 & 63 & 63 & 33 & 32 \\
\hline 1025 & 64 & 72 & 66 & 64 & 64 & 33 & 31 \\
\hline 1030 & 8 & 10 & 8 & 4 & 8 & 26 & 16 \\
\hline 1061 & 3 & 4 & 3 & 3 & 3 & 18 & 5 \\
\hline 1067 & 2 & 3 & 2 & 2 & 2 & 19 & 6 \\
\hline 1073 & 1 & 1 & 1 & 1 & 1 & 21 & 4 \\
\hline 1080 & 61 & 69 & 63 & 51 & 61 & 36 & 39 \\
\hline 1081 & 62 & 70 & 65 & 62 & 62 & 34 & 33 \\
\hline 1112 & 56 & 53 & 58 & 57 & 56 & 39 & 36 \\
\hline 1117 & 59 & 67 & 62 & 52 & 59 & 38 & 35 \\
\hline
\end{tabular}

A correlation matrix is constructed in order to measure correlation between each two decision making techniques. The correlation matrix is obtained based upon Spearman's rank correlation coefficient. The Correlation matrix is depicted in Table 5. The maximum five spearman's rank correlation coefficients are between (WSM, COPRAS), (WSM, PROMETHEE II), (VIKOR, PROMETHEE II), (COPRAS, PROMETHEE II) and (WSM, TOPSIS). The minimum five spearman's rank correlation coefficients are between (PROMETHEE II, ELECTRE I), (ELECTRE I, VIKOR), (ELECTRE I, WSM), (ELECTRE I, COPRAS) and (ELECTRE I, TOPSIS). Average correlation coefficients for WSM, GRA, TOPSIS, VIKOR, COPRAS, ELECTRE I, PROMETHEE II are 0.791, 0.425, 0.786, 0.771, $0.791,0.317$ and 0.768 , respectively. Results show that there is a perfect match between ranking obtained from WSM and COPRAS. On the other hand, the correlation between ELECTRE I and PROMETHEE II is the lowest one. WSM and COPRAS have the highest average correlation, which illustrates these methods provides the nearest possible consensus ranking. On the contrary, ELECTRE I and GRA have the least correlation.

Table 6

Correlation matrix between each two multi-criteria decision making techniques

\begin{tabular}{lccccccc}
\hline Decision making method & WSM & GRA & TOPSIS & VIKOR & COPRAS & ELECTRE I & PROMETHEE II \\
\hline WSM & 1.000 & 0.474 & 0.986 & 0.986 & 1.000 & 0.315 & 0.987 \\
GRA & 0.474 & 1.000 & 0.454 & 0.384 & 0.474 & 0.365 & 0.402 \\
TOPSIS & 0.986 & 0.454 & 1.000 & 0.982 & 0.986 & 0.336 & 0.977 \\
VIKOR & 0.986 & 0.384 & 0.982 & 1.000 & 0.986 & 0.303 & 0.987 \\
COPRAS & 1.000 & 0.474 & 0.986 & 0.986 & 1.000 & 0.315 & 0.987 \\
ELECTRE I & 0.315 & 0.365 & 0.336 & 0.303 & 0.315 & 1.000 & 0.271 \\
PROMETHEE II & 0.987 & 0.402 & 0.977 & 0.987 & 0.987 & 0.271 & 1.000 \\
\hline
\end{tabular}

Inferred group decision making results calculated from additive ranking rule and multiplicative ranking rule are shown in Table 6 . As shown in Table 6, the rankings obtained based on the additive ranking 
rule and multiplicative ranking rule are very similar. Results show that the ranking of the first three alternatives is the same for the two group decision making techniques. The maximum correlation between decision making techniques and aggregated decision making obtained from additive ranking rule is for WSM, COPRAS and TOPSIS, respectively, whereas the correlation is $0.989,0.989$ and 0.979 , respectively. The maximum correlation between decision making techniques and aggregated decision making obtained from multiplicative ranking rule is for TOPSIS, WSM and COPRAS, respectively, whereas the correlation is $0.9647,0.9643$ and 0.9643 , respectively. This proves the previous results obtained from the correlation matrix that rankings obtained from WSM, COPRAS and TOPSIS are very similar to the final ranking of the solutions. Thus, WSM, COPRAS and TOPSIS are the best MCDM methods that succeeded in analyzing and solving the current problem. The description of the first five alternatives is illustrated in Table 7.

Table 7

Ranking obtained from group decision making

\begin{tabular}{lllll}
\hline Alternative no. & $\begin{array}{l}\boldsymbol{r}^{\boldsymbol{G}} \text { (Additive } \\
\text { ranking rule) }\end{array}$ & Group ranking & $\begin{array}{l}\boldsymbol{r}^{\boldsymbol{G}} \text { (Multiplicative ranking } \\
\text { rule) }\end{array}$ & Group ranking \\
\hline 1025 & 56.286 & 67 & 53.620 & 67 \\
1030 & 11.429 & 8 & 9.774 & 8 \\
1061 & 5.571 & 3 & 4.343 & 3 \\
1067 & 5.143 & 2 & 3.420 & 2 \\
1073 & 4.286 & 1 & 1.883 & 1 \\
1080 & 54.286 & 63 & 52.893 & 63 \\
1081 & 55.429 & 64 & 53.267 & 64 \\
1112 & 50.714 & 58 & 49.910 & 58 \\
1117 & 53.143 & 61 & 51.795 & 62 \\
1121 & 10.571 & 7 & 9.158 & 7 \\
\hline
\end{tabular}

\section{Table 8}

Description of alternatives with the first five rankings

\begin{tabular}{llllll}
\hline Alternative no. & Optimal Solutions & $\begin{array}{l}\text { Total } \\
\text { Duration } \\
\text { (days) }\end{array}$ & $\begin{array}{l}\text { Life cycle Cost } \\
\text { (LE/year) }\end{array}$ & Environmental Impact Primary Energy \\
(MJ) & & & \\
\hline 1073 & $6,6,6,2,4,6,3,3,15,4,3,2,14,7,1$ & 143 & $1,615,859$ & 25.78 & $54,134,262$ \\
1067 & $6,6,6,4,4,6,1,2,15,4,3,2,14,7,1$ & 143 & $1,587,842$ & 25.876 & $55,834,542$ \\
1061 & $6,6,6,4,4,6,3,2,15,4,3,2,14,7,1$ & 143 & $1,586,999$ & 25.911 & $55,880,935$ \\
1126 & $6,6,6,4,3,6,1,3,15,4,3,2,6,7,1$ & 144 & $1,671,097$ & 24.587 & $53,676,965$ \\
1292 & $4,6,6,4,3,6,1,3,15,4,3,2,6,7,1$ & 147 & $1,670,240$ & 24.58 & $53,639,628$ \\
\hline
\end{tabular}

Robustness measure is used to measure robustness of the decision making techniques. Four scenarios were assumed for each attribute. Each attribute is increased by $20 \%, 40 \%, 60 \%$ and $80 \%$. The robustness measure calculated using Spearman's rank correlation coefficient and Kendall's tau rank correlation is depicted in Table 8. Analysis of the results illustrates that PROMETHEE II is the most robust model. On the other hand, GRA is the least robust model.

\section{Table 9}

Robustness measure of multi-criteria decision making techniques

\begin{tabular}{ll}
\hline Decision-Making Technique & $\boldsymbol{R M}$ (Robustness Measure) \\
\hline WSM & 0.778 \\
COPRAS & 0.765 \\
TOPSIS & 0.767 \\
VIKOR & 0.721 \\
GRA & 0.481 \\
ELECTRE I & 0.523 \\
PROMETHEE II & 0.846 \\
\hline
\end{tabular}

The distinguishing coefficient in GRA ranges from 0 to 1 . Different values are assumed for distinguishing coefficient which are: $0.1,0.3,0.5,0.7$, and 0.9 . The effect of different values of distinguishing coefficient on the ranking of alternatives is depicted in Figure 5. The value of the weight 
of decision making strategy in VIKOR is between 0 and 1. Different values for maximum group utility are assumed which are $0.1,0.3,0.5,0.7$ and 0.9 . The effect of different values of the weight of decision making strategy on the ranking of alternatives is illustrated in Figure 6. Results show that distinguishing coefficient in GRA has much more impact on the ranking of alternatives than the maximum group utility coefficient in VIKOR. The distinguishing coefficient causes more variations on the ranking of alternatives than the maximum group utility coefficient.

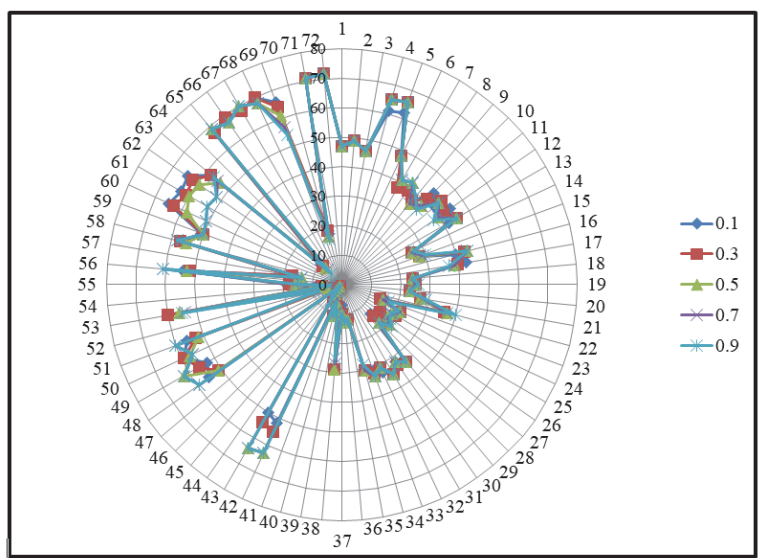

Fig. 5. Ranking of alternatives for different maximum group utility coefficients

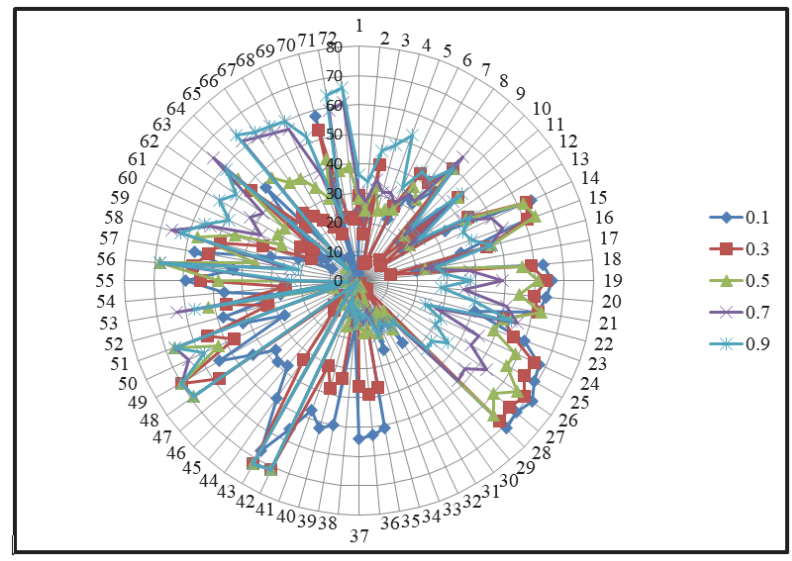

Fig. 6. Ranking of alternatives for different distinguishing coefficients

Sensitivity analysis is performed in order to determine the most sensitive attributes and most sensitive alternatives based on their sensitivity coefficients. The first stage is to calculate $\left(\chi_{k, i, j}\right)$ for each pair of alternatives. $\chi_{k, i, j}$ represents absolute change in criteria weights. The second stage is to calculate $\left(\chi^{\prime}{ }_{k, i, j}\right)$ which represents percentage change in criteria weights. $\chi^{\prime}{ }_{k, i, j}$ for alternative 1 is depicted in Table 9. The first alternative refers to alternative number 98 . The "N/F" indicates that the corresponding value does not satisfy constraint. Percent any can be found by looking for the smallest change in relative values $\left(\chi_{k, i, j}^{\prime}\right)$ for all alternatives which corresponds to $0.846 \%$, therefore percent any criteria is life cycle cost criteria. Percent top can be found by looking for the smallest change in relative values $\left(\chi_{k, i, j}^{\prime}\right)$ in the best ranking alternative which corresponds to $36.232 \%$, therefore percent top criteria is primary energy criteria.

\section{Table 10}

Some possible values of $\chi^{\prime}{ }_{\mathbf{k}, \mathbf{i}, \mathbf{j}}$ for the first alternative (percentage values)

\begin{tabular}{lllll}
\hline Pair of alternatives & Criteria 1 & Criteria 2 & Criteria 3 & Criteria 4 \\
\hline A1-A2 & N/F & N/F & N/F & -56.0241 \\
A1-A3 & N/F & 55.30966 & -689.479 & -37.5521 \\
A1-A4 & N/F & N/F & -790.151 & -92.4753 \\
A1-A5 & N/F & N/F & -487.225 & -101.141 \\
\hline
\end{tabular}

Criticality degrees and sensitivity coefficients of four attributes are illustrated in Table 10. $D_{4}{ }^{\prime}=5.87 \%$ represents minimum change in weight of environmental impact criteria such that ranking of pair of alternatives is reversed. Results show that if environmental impact changed by $5.87 \%$, ranking of alternatives will change. The most sensitive attribute is the one with the highest sensitivity coefficient. Thus, the most sensitive attribute is the lifecycle cost followed by primary energy then environmental impact and finally total duration.

Table 11

Criticality degrees and sensitivity coefficients of attributes

\begin{tabular}{cllll}
\hline Coefficient Criteria & Total Duration & Lifecycle Cost & Environmental Impact & Primary Energy \\
\hline$D_{k}^{\prime}$ & $7.125 \%$ & $0.984 \%$ & $5.87 \%$ & $1.1 \%$ \\
$\operatorname{sens}\left(c_{k}\right)$ & 0.14 & 1.015 & 0.17 & 0.908 \\
\hline
\end{tabular}


The proposed sensitivity measure is used to measure the sensitivity of different attributes. Sensitivity measures for different criteria are shown in Table 11. Primary energy is the most sensitive attribute followed by cost followed by environmental impact and finally time in WSM, COPRAS, TOPSIS and PROMETHEE II. GRA introduces different ranking as Primary energy is the most sensitive attribute followed by time followed by cost and finally environmental impact. The proposed sensitivity measure methodology introduces different ranking in WSM from Triantaphyllou and Sánchez approach.

\section{Table 12}

Sensitivity measures of different attributes for different multi-criteria decision making techniques

\begin{tabular}{llllll}
\hline Attribute & WSM & COPRAS & TOPSIS & GRA & PROMETHEE II \\
\hline Time & 1.004 & 1.004 & 1 & 1.876 & 1.042 \\
Cost & 1.532 & 1.532 & 1.555 & 1.728 & 2.213 \\
Environmental impact & 1.014 & 1.014 & 1.001 & 1.541 & 1.089 \\
Primary energy & 2.098 & 2.34 & 2.337 & 6.314 & 3.312 \\
\hline
\end{tabular}

The second phase is to determine the most sensitive alternatives. Threshold values $\mathrm{T}_{i, j, k}^{\prime}$ in relative terms are calculated for each pair of alternatives. $T_{i, j, k}^{\prime}$ for the first alternative represents $T_{i, j, k}^{\prime}$ for alternative number 98 . $\mathrm{T}_{1,1,4}^{\prime}=11.89161 \%$ indicates that $a_{1,1}$ must decrease by $11.89161 \%$ so that A4 (alternative number 104) become more preferable than A1 (alternative number 98). The "N/F" indicates that the corresponding value does not satisfy constraint. Threshold values $\mathrm{T}_{i, j, k}^{\prime}$ are depicted in Table 12.

\section{Table 13}

Threshold values $\mathrm{T}_{\mathbf{i}, \mathbf{j}, \mathbf{k}}^{\prime}$ in relative terms for the first alternative (percentage values)

\begin{tabular}{lllll}
\hline Pair of alternatives & Criteria 1 & Criteria 2 & Criteria 3 & Criteria 4 \\
\hline A1-A2 & 11.89161 & 1.081282 & 4.814439 & 0.703877 \\
A1-A3 & -12.5554 & -1.14164 & -5.0832 & -0.74317 \\
A1-A4 & N/F & 11.84031 & 52.71932 & 7.707625 \\
A1-A5 & N/F & 12.97452 & 57.76941 & 8.445953 \\
\hline
\end{tabular}

Sensitivity coefficients of some alternatives are illustrated in Table 13. The most sensitive alternative is the alternative with the highest sensitivity coefficient. The most sensitive alternative is alternative 1371 where its sensitivity coefficient is 99.312 . The least sensitive alternative is alternative 436 where its sensitivity coefficient is 0.571 . The corresponding criticality degree for alternative $1371\left(\Delta^{\prime}{ }_{51,2}\right)$ is $0.01007 \%$. This criticality degree indicates that $0.01007 \%$ is the minimum change that occurs for measure of performance $\left(a_{51,2}\right)$ such that the ranking of alternative 1371 changes.

\section{Table 14}

Sensitivity coefficients of some alternatives

\begin{tabular}{lccc}
\hline Alternative no. & $\boldsymbol{s e n s}\left(\boldsymbol{a}_{\boldsymbol{i j}}\right)$ & Alternative no. & $\boldsymbol{s e n s}\left(\boldsymbol{a}_{\boldsymbol{i j}}\right)$ \\
\hline 436 & 0.571 & 1251 & 2.126 \\
442 & 29.028 & 1261 & 36.563 \\
447 & 23.358 & 1262 & 99.283 \\
454 & 29.837 & 1267 & 68.519 \\
477 & 20.831 & 1268 & 23.574 \\
505 & 3.636 & 1292 & 12.239 \\
605 & 17.713 & 1293 & 73.660 \\
610 & 23.692 & 1317 & 73.680 \\
620 & 6.598 & 1357 & 39.305 \\
654 & 23.681 & 1371 & 99.312 \\
\hline
\end{tabular}


Another sensitivity analysis is conducted to determine the most sensitive stage in a specific assembly in producing emissions. The sub clusters are phases of construction process which are: manufacturing phase, construction phase, maintenance phase, recycling/reuse phase and deconstruction/demolition phase. The main clusters are assemblies of construction project which are: beams, slabs, cladding, painting, etc. AHP is used to determine the weights of sub clusters and main clusters. Consistency ratio of the sub clusters is 0.0469 which is less than 0.1 . Thus, the consistency ratio is satisfactory. Consistency ratio of the main clusters is 0.0455 which is less than 0.1 . Thus, the feedback of the respondents is consistent. The most sensitive five stages in producing greenhouse gases as well as their weights are shown in Table 14. Results show that manufacturing phase in walls is the most sensitive stage in producing greenhouse gases and its sensitivity coefficient is $0.158\left(D_{1}^{\prime}=6.3291 \%\right) . D_{1}{ }^{\prime}=$ $6.3291 \%$ means that if quthe antity of greenhouse gases of manufacturing of the walls changed by $6.3291 \%$, the ranking of alternatives will be reversed.

\section{Table 15}

Most sensitive project stages in producing greenhouse gases

\begin{tabular}{llll}
\hline Criteria & Weight (\%) & & $\boldsymbol{\operatorname { s e n s }}\left(\boldsymbol{c}_{\boldsymbol{k}}\right)$ \\
\hline Walls- Manufacturing & 9.68 & 0.158 & \\
Columns- Manufacturing & 5.69 & 0.112 & \\
Walls- Maintenance & 1.54 & 0.057 & \\
Walls- Demolition and deconstruction & 4.26 & 0.0403 & \\
\hline Foundations' Insulation- Manufacturing & 1.08 & 0.039 & \\
\hline
\end{tabular}

The most sensitive five stages in acidification potential are depicted in Table 15. Results show that manufacturing phase in walls is the most sensitive stage in acidification potential occurrence and its sensitivity coefficient is 6.2608 . The most sensitive five stages in producing particular matter are illustrated in Table 16. The most sensitive stage in producing particular matter is manufacturing phase in columns and its sensitivity coefficient is equal to 0.1278 .

Table 16

Most sensitive project stages in acidification potential occurrence

\begin{tabular}{llll}
\hline Criteria & Weight (\%) & & $\left.\boldsymbol{s e n s}_{(\boldsymbol{k}}\right)$ \\
\hline Walls- Manufacturing & 9.68 & 6.26 & \\
Foundations' Insulation- Manufacturing & 1.08 & 3.419 & \\
Walls- Construction & 2.67 & 1.432 & \\
Columns- Demolition and deconstruction & 2.5 & 1.351 & \\
Foundations' Insulation- Construction & 0.3 & 1.197 & \\
\hline
\end{tabular}

Table 17

Most sensitive project stages in producing particular matter

\begin{tabular}{llll}
\hline Criteria & Weight (\%) & $\left.\boldsymbol{s e n s}_{(\boldsymbol{k}}\right)$ \\
\hline Columns- Manufacturing & 5.69 & 0.127 & \\
Ceiling Finishing- Manufacturing & 1.45 & 0.075 & \\
Slabs- Demolition and deconstruction & 5.02 & 0.053 & \\
Columns- Demolition and deconstruction & 2.5 & 0.042 & \\
Painting- Manufacturing & 3.15 & 0.039 & \\
\hline
\end{tabular}

Results of Kolmogorov-Smirnov test, Anderson Darling test and Chi-squared test for slabs are illustrated in Table 17. Analysis of tests shows that the distribution that most fit the dataset is the normal distribution. Number of iterations used in Monte Carlo simulation is 1000 iterations. Monte Carlo simulation results are depicted in Figure 7. Average greenhouse gases footprint (concrete scenario) is $455.429 \mathrm{Kg} \mathrm{CO} 2 / \mathrm{m}^{2}$. Standard deviation equals to 75.096. Minimum greenhouse gases footprint equals to $147.903 \mathrm{Kg} \mathrm{CO} / \mathrm{m}^{2}$. Maximum greenhouse gases footprint equals to $722.536 \mathrm{Kg} \mathrm{CO} 2 / \mathrm{m}^{2}$. Range equals to $574.631 \mathrm{Kg} \mathrm{CO}_{2} / \mathrm{m}^{2}$. 
Table 18

Goodness of fit tests for probability distributions for slabs

\begin{tabular}{lllllll}
\hline $\begin{array}{l}\text { Probability density } \\
\text { functions }\end{array}$ & $\begin{array}{l}\text { Kolmogorov- } \\
\text { Smirnov test }\end{array}$ & Rank & $\begin{array}{l}\text { Anderson } \\
\text { Darling test }\end{array}$ & Rank & $\begin{array}{l}\text { Chi-squared } \\
\text { test }\end{array}$ & Rank \\
\hline $\begin{array}{l}\text { Normal distribution } \\
\text { Lognormal }\end{array}$ & 0.1133 & 1 & 0.20795 & 1 & 0.07447 & 2 \\
$\begin{array}{l}\text { distribution } \\
\text { Weibull distribution }\end{array}$ & 0.12179 & 2 & 0.25204 & 3 & 0.06089 & 1 \\
Uniform distribution & 0.12187 & 3 & 0.22073 & 2 & 0.07897 & 3 \\
Triangular distribution & 0.15352 & 4 & 0.36649 & 4 & 0.0915 & 4 \\
Beta distribution & 0.18495 & 5 & 2.7625 & 5 & 0.09632 & 5 \\
\hline
\end{tabular}

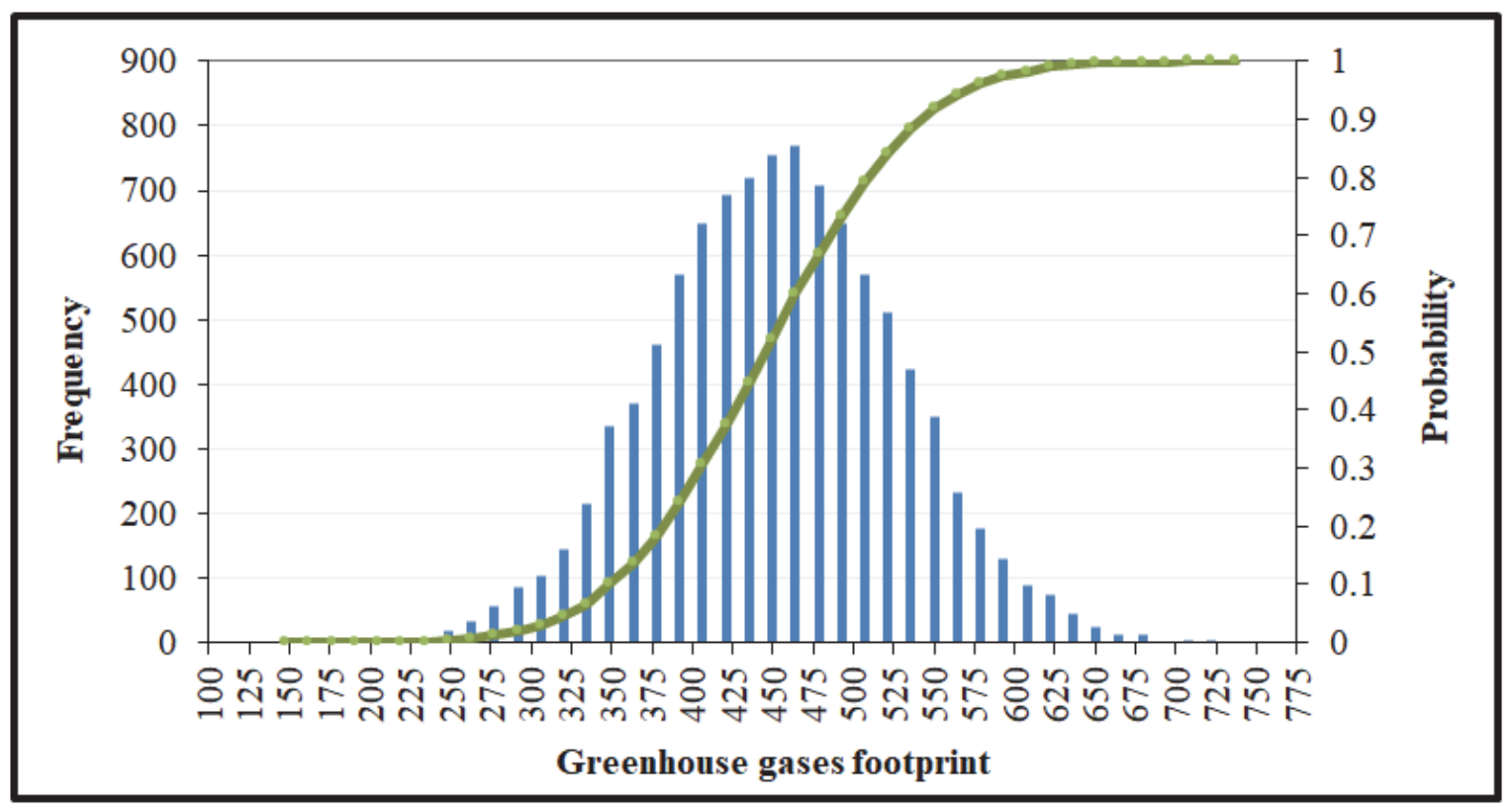

Fig. 7. Probability distribution of greenhouse gases footprint

\section{Conclusions}

Building-related environmental issues have increased significantly in the last few years. Environmentally harmful activities differ from one industry to another but the construction industry has established itself as one of the major sources of environmental emissions. This paper presented a decision tool that enables decision makers to select the most sustainable construction alternatives based on a hybrid model that combined both multi-objective optimization and multi-criteria decision making. Multi-objective optimization is performed using NSGA-II in order to select the most feasible solutions considering project duration, project life cycle cost, project overall emissions and total project primary energy as objective functions. A novel hybrid MCDM is proposed to define the best solution among the set of the Pareto optimal solutions using seven MCDM methods which are: WSM, COPRAS, GRA, TOPSIS, VIKOR, ELECTRE I and PROMETHEE II. A final ranking of the solutions is obtained using additive and multiplicative rules. A robustness measure is introduced to investigate the stability of the MCDM methods against the variations in parameters of the model. Sensitivity analysis is performed to determine the most sensitive attribute, the most sensitive measure of performance and the most sensitive stage of the construction process that affects environmental emissions. The introduced sensitivity analysis provides a full ranking of attributes and alternatives based on sensitivity coefficients and measures. 
Finally, Monte Carlo simulation is used to account for uncertainties and variations in the calculation of equivalent carbon dioxide emissions. A case study of academic building is presented in order to demonstrate the practical feature. The analysis of the present study reveals the following: 1) selecting construction alternatives other than conventional materials can substantially minimize the emissions associated with the construction process, 2) the rankings obtained from WSM, TOPSIS and COPRAS are very similar to the final ranking of the solutions. On the other hand, the rankings obtained from GRA and ELECTRE I are very distinct from the final ranking, i.e., WSM, COPRAS and TOPSIS are the best MCDM methods to provide problem solution, 3) PROMETHEE II is the most robust MCDM method against perturbations in the parameters of the model while GRA is the least robust MCDM method, 4) The distinguishing coefficient of GRA causes more variations on ranking of alternatives than the maximum group utility coefficient of VIKOR method, 5) Primary energy is the most sensitive attribute while time is the least sensitive attribute, 6) manufacturing phase in walls is the most sensitive stage that affects greenhouse gases and acidification while manufacturing phase in columns is the most sensitive stage responsively for particular matter, and 7) Average greenhouse gases footprint of conventional scenario is $455.429 \mathrm{Kg} \mathrm{CO} / \mathrm{m}^{2}$ based on Monte Carlo sampling.

\section{References}

Abdallah, M., El-rayes, K., \& Clevenger, C. (2015). Minimizing Energy Consumption and Carbon Emissions of Aging Buildings. Procedia Engineering, 118, 886-893.

Akyene, T. (2012). Cell Phone Evaluation Base on Entropy and TOPSIS. Interdisciplinary Journal of Research In Business, 1(12), 9-15.

Autodesk, Autodesk Revit 2015. Available at: http://www.autodesk.com/education/free-software/revit (accessed Dec 29, 2014).

Athena Sustainable Materials Institute, Athena Impact Estimator 5.0.0105. Available at: http:/calculatelca.com/software/impact-estimator/download-impact-estimator/ (accessed Feb 1, 2015).

Banerjee, R., \& Ghosh, D. (2013). Faculty Recruitment in Engineering Organization Through Fuzzy Multi-Criteria Group Decision Making Methods. International Journal of u-and e-Service. Science and Technology, 6, 139-154.

Bogdanovic, D., Nikolic, D., \& Ivana, I. (2012). Mining method selection by integrated AHP and PROMETHEE method. Anais da Academia Brasileira de Ciencias, 84; 219-233.

Barati, K. \& Shen, X. (2017). Optimal driving pattern of on-road construction equipment for emissions reduction, Procedia Engineering, 180, 1221-1228.

Chakraborty, R., Ray, A., \& Dan, P.K. (2013), Multi criteria decision making methods for location selection of distribution centers. International Journal of Industrial Engineering Computations, 4, 491-504.

Chen, J., Hsu, S., Luo, Y., \& Skibniewski, M. J. (2012). Knowledge Management for Risk Hedging by Construction Material Suppliers. Journal of Management in Engineering, 28(3), 273-280.

Cho., S., \& Chae, C. (2016). A Study on Life Cycle $\mathrm{CO}_{2}$ Emissions of Low-Carbon Building in South Korea. Sustainability, 8 (579), 1-19.

Cristóbal, J.R.S. (2011). Multi-criteria decision-making in the selection of a renewable energy project in spain: The Vikor method. Renewable Energy, 36(2), 498-502.

Dean, B., Dulac, J., Petrichenko, K., \& Graham, P. (2016). Towards zero-emission efficient and resilient buildings Global Status Report 2016, Global Alliance for Buildings and Construction, Available at: http://www.planbatimentdurable.fr/IMG/pdf/gabc report.pdf (accessed June 24, 2018).

Dragisa, S., Bojan, D., \& Mira, D. (2013). Comparative Analysis of Some Prominent MCDM Methods: A case of Ranking Serbian banks. Serbian Journal of Management, 8(2), 213-241.

Heidrich, O., Reckien, D., Olazabal, M., Foley, A., Salvia, M., Hurtado, S. D. G., Orru, H., Flacke, J., Geneletti, D., Pietrapertosa, F., Hamann, J. J., Tiwary, A., Feliu, E., \&. Dawson, R. J. (2016). National climate policies across Europe and their impacts on cities strategies. Journal of 
Environmental Management, 168, 36-45.

Huang, W., Li, F., \& Cui, S. (2017). Carbon Footprint and Carbon Emission Reduction of Urban Buildings : A Case in Xiamen City, China. Procedia Engineering 198, 1007-1017.

Kuo, Y, Yang. T, \& Huang, G.W. (2008). The Use of Grey Relational Analysis in Solving Multiple Attribute Decision-making Problems. Computers and Industrial Engineering, 55, 80-93.

Motuzienệ, V., Rogoza, A., Lapinskiene, V., \& Vilutiene, T. (2016). Construction solutions for energy efficient single-family house based on its life cycle multi-criteria analysis : a case study. Journal of Cleaner Production, 112, 532-541

Mulliner, E., Smallbone, K., \& Maliene, V. (2013). An assessment of sustainable housing affordability using a multiple criteria decision making method. Omega, 41, 270-279.

Olivier, J. G. J., Janssens-Maenhout, G., Muntean, M., \& Peters, J. A. H. W. (2016). Trends in global $\mathrm{CO}_{2}$ emissions 2016, PBL Netherlands Assessment Agency, European Commision Joint Research Centre, Available at: http://edgar.jrc.ec.europa.eu/news_docs/jrc-2016-trends-in-global-co2emissions-2016-report-103425.pdf (accessed June 24, 2018).

Parker, C. F., \& Karlsson, C. (2018). The UN climate change negotiations and the role of the United States: assessing American leadership from Copenhagen to Paris The UN climate change negotiations and the role of the United States : assessing American leadership from Copenhagen to Paris. Environmental Politics, 27 (3), 519-540.

Pires, M.B, Silva, J. V. M., \& Gupta, P. D. (2016). Heat Waves In Non-Conventional Areas , Climate Change And Disease Load: A Review. Journal of Cell and Tissue Research, 16 (2), 5705-5711.

Saaty, T.L. (1980). Analytic hierarchy process, McGraw-Hill, New York.

Seo, M., Kim, T., Hong, G., \& Kim, H. (2016). On-Site Measurements of $\mathrm{CO}_{2}$ Emissions during the Construction Phase of a Building Complex. Energies, 9(8), 1-13.

Triantaphyllou, E., Shu, B., Nieto Sanchez, S., \& Ray, T. (1998). Multi-criteria decision making: an operations research approach. Encyclopedia of Electrical and Electronics Engineering, 15 175-186.

Triantaphyllou, E. \& Sánchez, A. (1997). A sensitivity analysis approach for some deterministic multicriteria decision making methods. Decision Sciences, 28(1), 151-194.

Visual PROMETHEE 1.4. VPSolutions, Available at: http://www.promethee-gaia.net/software.html (accessed Aug 25, 2015).

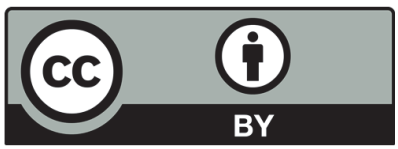

C 2019 by the authors; licensee Growing Science, Canada. This is an open access article distributed under the terms and conditions of the Creative Commons Attribution (CC-BY) license (http://creativecommons.org/licenses/by/4.0/). 